\title{
Novas estratégias em educação: avaliação da técnica Tribunal do Júri na capacitação de conselheiros na área de saúde da mulher em Santa Catarina, Brasil
}

\author{
New educational strategies: evaluation of the \\ Jury Trial technique for training council members \\ in women's health in Santa Catarina, Brazil
}

Eleonor Minho Conill 1

Magda Duarte dos Anjos Scherer 2

\footnotetext{
1 Departamento de Saúde Pública, Núcleo de Apoio à Municipalização e Implementação do SUS em Santa Catarina, Universidade Federal de Santa Catarina. Rua Vento Sul 306, Florianópolis, SC 88063-075, Brasil. eleonorc@bol.com.br 2 Associação Casa da Mulher Catarina, Departamento de Serviço Social, Universidade Federal de Santa Catarina. Rua Desembargador Pedro Silva 2630, bloco C/21, Florianópolis, $S C$ 88080-701, Brasil. magscherer@uol.com.br
}

\begin{abstract}
This article describes and evaluates the Jury Trial technique, an innovative educational instrument used in a pilot workshop on Social Control and Gender by health council members in Greater Metropolitan Florianópolis, Santa Catarina, Brazil. The reliability and validity were studied based on the participants' opinions, complemented by qualitative observation of the work. There was consensus in acceptance of the technique based on "acquisition of knowledge" and the fact that it was participatory, democratic, and dynamic. The positive evaluation agrees with a previous study that interviewed municipal health secretaries, with a smaller preference of formal cognitive activities that were also part of the workshop. The article concludes by emphasizing the importance of this innovative technique in training programs, since it is accepted by different target publics, allows for designing the program contents, and is useful in relation to new and controversial issues since it favors practical and reflexive experiences.
\end{abstract}

Key words Strategies; Evaluation; Health Education

Resumo Descreve-se e avalia-se a técnica Tribunal do Júri, instrumento educativo inovador utilizado em uma oficina piloto sobre Controle Social e Gênero para conselheiros de saúde da Grande Florianópolis, Santa Catarina, Brasil. Estudaram-se sua confiabilidade e validade utilizando a opinião dos participantes complementado com observação qualitativa dos trabalhos. Houve unanimidade na aceitação da técnica por parte dos conselheiros pela "aquisição de conhecimentos" e "por ser participativa, democrática e dinâmica". A avaliação positiva coincide com trabalho anterior feito com secretários municipais, notando-se menor preferência por atividades cognitivas formais que também compunham a oficina. Conclui-se reforçando a importância do uso dessa inovação em capacitações, por ser aceita por públicos distintos, permitir o mapeamento de conteúdo programático e ser útil face a temáticas novas e polêmicas ao favorecer vivências práticas e reflexivas.

Palavras-chave Estratégias; Avaliação; Educação em Saúde 


\section{Introdução}

Descreve-se e analisa-se, aqui, a aplicação da técnica Tribunal do Júri na capacitação de conselheiros de saúde, a maior parte procedente da região da Grande Florianópolis. A técnica foi escolhida como o principal instrumento educativo de uma oficina sobre controle social e gênero. Tratava-se de um projeto-piloto intitulado Controle Social do SUS e Saúde da Mulher: Oficina Didática para Conselheiros Municipais de Saúde e visava a desencadear capacitação desse tipo em todo o Estado (Luna et al., 1999). As atividades foram realizadas pela Associação Casa da Mulher Catarina, em parceria com o Ministério da Saúde (MS), Secretaria de Estado da Saúde de Santa Catarina (SES-SC), Secretaria Municipal de Saúde de Florianópolis e Universidade Federal de Santa Catarina (UFSC), em dezembro de 1999.

O objetivo era fortalecer a atuação dos conselheiros como catalisadores do exercício da cidadania, instrumentalizando-os para que pudessem compreender o espaço dos Conselhos como locus de manifestação de interesses plurais, tais como classe, gênero, raça/etnia, orientação sexual. O pressuposto era que tais interesses são freqüentemente conflitivos, mas negociáveis, desde que tenham como horizonte as políticas públicas e de saúde da mulher, congruentes com os princípios do SUS.

Em 1997, aplicou-se o Tribunal do Júri ao conjunto de secretários municipais de saúde do Estado, para sensibilização à questão dos deveres do administrador público, como parte introdutória de um ciclo de formação para dirigentes municipais (Conill et al., 1998). Conforme veremos a seguir, esta técnica favorece a aquisição de conhecimentos e a reflexão acerca de atitudes sobre determinado tema utilizando a dramatização. Dos 156 participantes, 98\% foram favoráveis à inovação por considerá-la dinâmica/ participativa (31\%), educativa/reflexiva (27\%) e traduzir a realidade $(24 \%)$. Sugeriu-se a validade de técnicas que trabalhem novas formas de comunicação, explorando, para além do cognitivo, aspectos vivenciais e afetivos.

O uso de técnicas inovadoras na área da saúde vem sendo enfatizado mas continua ainda incipiente. Algumas atividades de aquecimento e desbloqueio, conhecidas como "técnicas quebra-gelo" são antigas, sendo às vezes usadas para facilitar a integração de grupos. Um leque diversificado e criativo dessas estratégias educacionais surgiu mais recentemente, em encontros do movimento de mulheres, na área de educação de saúde e da sexualidade humana, onde Oficinas de Trabalho com esse enfoque tendem a integrar ou substituir aulas, painéis ou conferências.

Estas técnicas, compreendem um conjunto de dinâmicas que favorecem a aprendizagem através da socialização de vivências utilizando-se a fala, a arte e o movimento como recursos (linha da vida, túnel do tempo, Oficinas com massa de modelar, desenhos, confecção de máscaras, jogos e dramatizações, são alguns exemplos). No entanto, aspectos de seu desenvolvimento e de sua avaliação têm sido pouco sistematizados, encontrando-se um número reduzido de publicações (Grupo de Pesquisa e Educação Popular/Grupo Interinstitucional de Comunicação e Educação em Saúde de Santa Catarina, 2000; Regia et al., 1988; Vianna et al., 1991).

Segundo Cartwright \& Zander (1969, apud Busnello, 1986:16), uma entre as três concepções dadas ao termo dinâmica de grupo corresponde ao interesse aqui em foco, ou seja, “o conjunto de técnicas empregadas em programas de treinamento, planejadas para o desenvolvimento de habilidades, de estabelecer boas relações humanas e de dirigir comissões e grupos". Essas técnicas incluiriam o desempenho de papéis, as discussões em grupo, a observação e o feedback de processos coletivos.

Este entendimento coincide com o de Vitiello (1997), para quem as dinâmicas de grupo inserem-se nas metodologias participativas da educação, considerando-as como uma estratégia de sensibilização, uma vez que um indivíduo sensível aprenderia mais facilmente e com mais profundidade. As dinâmicas de grupo têm sua utilidade nas seguintes situações: abertura de trabalhos educativos, valorização de comportamentos, promoção de responsabilidades sociais e para o desenvolvimento da percepção do outro como indivíduo. Nada ensinaria melhor que a experiência acumulada ao longo da vida, mas o tempo é um limite importante nesse aprendizado. Essas técnicas facilitariam a síntese, reflexão e troca de experiências, permitindo que através de pequenas vivências se adquiram conhecimentos com maior maturidade $\mathrm{e}$ relativa rapidez.

Segundo Vitiello (1997), a expressão "dinâmica de grupo" apareceu pela primeira vez em 1944 com Kurt Lewin, que expandiu o campo da psicologia social a partir do estudo das relações interpessoais e intergrupais. Mas foi Jacó Levi Moreno que, entre 1922 e 1925, iniciou o uso de técnicas lúdicas para a psicoterapia de grupo e a aprendizagem de papéis. Em sua busca por conhecimento, o ser humano sempre tentou usar a ação, a imitação e a representação como meios para expressar-se. A necessidade 
de movimento se manifestou pelo aparecimento dos jogos nas diferentes culturas, todos revestidos de significados. A essência do jogo e das atividades lúdicas é a capacidade de assumir papéis e entrar em situações imaginárias com espontaneidade, recriando e descobrindo novas formas de atuação. No entanto, é importante que o indivíduo queira jogar e que esteja disponível para facilitar a liberação de sua espontaneidade criativa.

Este trabalho dá continuidade à discussão do uso de estratégias inovadoras em educação através do estudo de uma nova aplicação da técnica Tribunal do Júri. Tem como objetivos principais, verificar sua aceitação junto a um público distinto daquele analisado em pesquisa anterior (Conill et al., 1998), avaliando aspectos de sua operacionalização e utilidade. Após considerações de ordem metodológica, descreve-se a situação de saúde da mulher e do controle social no Estado, situando-se o contexto de sua aplicação. Em seguida, relatam-se a preparação e a realização da oficina com seus resultados.

Tem-se enfatizado a importância dos conselheiros na construção de uma esfera pública democrática assim como a necessidade de lhes serem asseguradas práticas educativas adequadas, de forma a fortalecer sua atuação (MS, 1999).

\section{Considerações metodológicas}

Enfocam-se, aqui, a confiabilidade, a validade de conteúdo e a validade de construção da técnica Tribunal do Júri através de um estudo de opinião e de observação junto ao público-alvo. De forma genérica, avaliar significa realizar um julgamento de valor a respeito de uma intervenção ou de seus componentes (Contandriopoulos et al., 1997). Embora o objeto deste estudo seja uma estratégia inovadora a ser utilizada com finalidades educativas, seu objetivo não é o de aferir rendimento ou resultados do processo de aquisição de conhecimentos em si.

A metodologia utilizada insere-se no que se denomina pesquisa de desenvolvimento, que visa a elaborar ou a melhorar intervenções, instrumentos, dispositivos ou métodos de medição existentes (Contandriopoulos et al., 1994). O foco, neste tipo de estudo, é a avaliação da qualidade da intervenção ou do dispositivo de medição envolvido, verificando-se sua confiabilidade e validade.

A confiabilidade refere-se à fidelidade ou possibilidade de sua repetição no tempo ou no espaço, obtendo-se os mesmos resultados; a validade, à precisão com que o fenômeno em estudo é apropriado. A validade diz respeito, por- tanto, à adequação entre o instrumento e o conceito teórico ou objeto que se quer medir ou intervir. Pode-se estimar a validade utilizando-se três tipos de avaliação: validade de conteúdo (conceitos adequados), validade do critério de predição (sensibilidade, especificidade) e validade de construção (operacionalização).

Para determinar a validade de conteúdo, recorre-se à opinião de especialistas ou da própria população-alvo, como foi o caso deste estudo. As variáveis usadas foram a aceitação e a percepção da utilidade da técnica, a comparação com outras atividades realizadas na oficina e a avaliação da estrutura e dos processos relacionados com seu desenvolvimento (local, material, tempo, monitores). Para fins de comparação com a avaliação feita no trabalho anterior, utilizou-se uma metodologia equivalente, com triangulação de método (dados quantitativos e qualitativos) e de fontes (observação, opinião).

Dos 22 municípios alvos do projeto, todos afirmaram possuir um Conselho organizado. Estimando-se uma média de 10 integrantes por Conselho, haveria um público potencial de 110 participantes, visando-se a cobrir $50 \%$ dos conselheiros. Compareceram ao evento 44, ou seja, em torno de $40 \%$ dos conselheiros previstos. As vagas não preenchidas foram oferecidas à Pastoral da Saúde, a outros municípios pólos do Estado e a representantes da Articulação Nacional de Trabalhadoras Rurais, totalizando um universo de 54 participantes, dos quais 40 responderam ao questionário de avaliação. Este era composto de 22 questões, a maior parte fechadas, organizadas em quatro blocos (identificação, avaliação da técnica, controle social, saúde da mulher). Incluía questões espelho de forma a aumentar a veracidade das afirmações. Um pesquisador externo também trabalhou como observador do evento, utilizando um roteiro prédeterminado, cotejando a análise temática desse material com as respostas do questionário.

\section{Saúde da mulher e o controle social em Santa Catarina}

Um estudo de Carvalho (1995) constatou a existência de cerca de 50 mil conselheiros, com 3 mil conselhos funcionando regularmente e 1.900 em situação precária. Santa Catarina foi apontado como o Estado cujos municípios mais avançaram na montagem de Conselhos Municipais de Saúde (CMS) (95\%).

Entretanto, dados de pesquisa local realizada em 1996 identificaram a implantação de 211 Conselhos, ou seja, $81 \%$ do total de municípios. Entrevistaram-se 395 conselheiros de $20 \%$ dos 
municípios com lei de criação do CMS, sendo $73 \%$ com segundo e terceiro grau completos, demonstrando um alto grau de escolaridade. Observou-se também que 48\% tinham formação e/ou trabalhavam na área da saúde, $40 \%$ participavam de partido político, $72,1 \%$ atuavam em movimentos sociais, $70 \%$ em entidade de classe (Funk et al., 2000).

De acordo com dados mais recentes (SESSC, 2001) todos os 293 municípios do Estado têm lei de criação do CMS com composição média de 10 conselheiros. Não se pode afirmar quantos estão de fato exercendo seu papel, mas apenas cerca de $15 \%$ cumpriam todos os requisitos, do ponto de vista da legislação, exigidos pela SES-SC.

Além dos Conselhos Municipais, constituem espaços formais do controle social o Conselho Estadual de Saúde (CES) e o Fórum Popular de Saúde. O primeiro conta com representação de duas entidades de mulheres: Associação Casa da Mulher Catarina e Articulação Nacional de Trabalhadoras Rurais. Em um estudo revisando as atas desse Conselho, verificou-se que o tema saúde da mulher apareceu apenas uma vez, como um informe a respeito da necessidade de revisão do percentual de cesarianas para hospitais de maior porte e complexidade. Não houve debate sobre o assunto (Luna et al., 2000).

Em 1998, os participantes do Encontro da Rede Feminista de Saúde e Direitos Reprodutivos elegeram o estímulo à presença do movimento de mulheres no controle social do SUS como prioridade. O argumento foi de que o movimento de mulheres brasileiro tem longa história de intervenção nas políticas públicas, com críticas e propostas em prol da saúde especialmente com respeito ao Programa de Assistência Integral à Saúde da Mulher (PAISM). A Rede elaborou um manual sobre os espaços de participação, tais como Conselhos e comitês de morte materna, comissões gestoras dos equipamentos de saúde, comissões legislativas e a mídia (Rede Nacional Feminista de Saúde e Direitos Reprodutivos, s.d.).

O PAISM (MS, 1984) representa um dos poucos programas no qual o movimento social encontrou um canal de representação e expressão em uma política social. Elaborado em 1984, já incorporava princípios de integralidade e universalização que surgiram posteriormente no SUS.

Após tentativas de implementação na década de 80 , as ações de saúde da mulher passam por um período de latência ou às vezes até de retrocesso. Enquanto o SUS avançava no plano jurídico-legal, o foco dessas ações na década de 90 parece ter se deslocado do concreto para a busca de consensos em torno de direitos sexuais e reprodutivos no âmbito dos direitos humanos e do desenvolvimento sustentável, discutidos na Conferência Internacional sobre População e Desenvolvimento, realizada no Cairo em 1994 e na 4a Conferência Mundial sobre a Mulher, realizada em Pequim, 1995.

Recentemente, a Área Técnica de Saúde da Mulher da Secretaria de Políticas de Saúde do MS divulgou um documento com as principais estratégias para o período 1999-2002 (MS, 1999). Na avaliação, destaca-se a heterogeneidade da cobertura e qualidade da assistência com a necessidade de que o PAISM seja revisto, articulando-o ao Programa Saúde da Família, principal estratégia governamental para reorganização da atenção básica (MS, 1994; 1998). São áreas prioritárias: gravidez, parto e puerpério, aborto, mortalidade materna, violência doméstica e sexual, doenças sexualmente transmissíveis e AIDS, câncer cérvico-uterino e de mama.

Peixoto (1977) analisou diferenças de mortalidade por sexo e causas de óbitos para Santa Catarina em 1995, utilizando o indicador dos anos potenciais de vida perdidos (APVP). Nos grupos de causas em que houve excesso de mortalidade feminina, estão a febre reumática e doença reumática do coração, a doença hipertensiva e a diabetes mellitus. O grupo de neoplasias malignas, quarta causa de APVP entre os homens, assume a segunda posição no sexo feminino, possivelmente porque as principais localizações de neoplasias na mulher ocorrem em idades mais jovens, segundo a autora. Dados levantados por Ortiga (1999) em Blumenau sugerem que a cobertura do exame preventivo no Estado é baixa. Esse parâmetro foi usado como indicador dos efeitos da municipalização na integralidade da atenção nesse município passando a cobertura de quatro para apenas $10 \%$ no período de 1994 a 1998.

A assistência ao parto no Brasil é marcada pelo recurso excessivo à cesariana, concentrando-se nas regiões Sudeste, Centro-Oeste e Sul as maiores proporções de parto por cesárea (MS, 1999). Santa Catarina tem uma proporção de $41,9 \%$ de cesáreas, inferior à média da região $(43,8 \%)$, mas superior à nacional $(40,2 \%)$. Quanto à proporção de gestantes com mais de seis consultas de pré-natal, o Estado fica abaixo da média da região $(51,2 \%)$, com uma cobertura da ordem de 45,5\% (MS, 1997). Já em 1988, Santa Catarina incluía-se entre aqueles estados com baixa cobertura e distorção no perfil de produção em obstetrícia, mostrando maior ênfase na internação do que nas consultas de pré-natal (Conill \& Meister, 1988). 


\section{Descrição da oficina: preparação e execução}

O projeto piloto cobriu a Capital e 21 municípios vizinhos, realizando-se contatos com os Secretários Municipais, por serem estes, em geral, os presidentes dos Conselhos. Sendo o principal centro de serviços do Estado, Florianópolis, com os três municípios mais próximos concentram aproximadamente $12 \%$ da população urbana estadual, da ordem de 5.349.580 (IBGE, 2001).

O preenchimento das 100 vagas oferecidas obedeceu, no primeiro prazo de inscrição, a dois critérios: representação dos segmentos que compõem os conselhos e participação de $50 \%$ dos conselheiros de cada município. Os principais aspectos identificados pela comissão organizadora para explicar a baixa adesão ao evento foram: dificuldades no fluxo de comunicação entre o presidente (em geral, o Secretário Municipal de Saúde) e os demais membros dos conselhos, falhas na divulgação, decorrentes do exíguo tempo após a liberação do financiamento, com retardo no uso de outros meios da comunicação. Alguns secretários referiram dificuldades em reunir o conselho para divulgação, alegando serem pouco atuantes e que sua existência cumpria exigências para habilitação nas modalidades de gestão municipal.

O material instrucional foi desenvolvido pela equipe da Casa da Mulher Catarina, selecionando-se e treinando-se monitores e observadores. Distribuíram-se Leis, Normas, material educativo do MS, cartilha sobre o SUS, elaborada para conselheiros, cartilha da Rede Feminista de Saúde e Direitos Reprodutivos.

Do programa final, constaram dois painéis e uma aula expositiva dialogada, mas com enfoque principal em três atividades: reuniões simuladas, troca de experiências e Tribunal do Júri, precedidas de uma dinâmica de aquecimento e seguidas de debates com especialistas. A divisão da carga horária entre atividades consideradas clássicas e inovadoras foi de 8 versus 10 horas.

Nas reuniões simuladas, participantes discutiram duas situações de um município fictício sobre o qual se fornecia uma síntese de dados básicos. Primeiro estavam em pauta a aprovação do Plano de Saúde e a programação de gastos que o Secretário desejava aprovar: reforma e ampliação de uma unidade do centro da cidade e aquisição de ambulância e pagamento de motorista. Para deliberar, os conselheiros deveriam discutir: (1) como definir as prioridades, (2) recomendariam a aprovação do plano sugerindo mudanças mesmo saben- do que o prazo de encaminhamento para o Ministério se esgotava em 12 dias? e (3) nesse caso, que recomendações fariam?

A segunda situação foi o caso de cobrança de ato cirúrgico remunerado pelo SUS.

Para a troca de experiências, utilizou-se um roteiro de itens sobre o funcionamento do Conselho, tais como eleição e conduta do presidente, freqüência e dinâmica das reuniões, participação e dificuldades identificadas.

A técnica Tribunal do Júri simula um julgamento, a fim de propiciar vivências, posições e reflexões acerca de uma temática - neste caso, o papel dos conselheiros no exercício do controle social. É composta pelos seguintes personagens: três advogados de defesa, três advogados de acusação (promotoria), três testemunhas de acusação e três testemunhas de defesa, sete jurados, um réu, um juiz e um escrivão. Os demais presentes são incorporados como grupo de apoio para defesa e acusação ou podem assumir outros papéis (imprensa, policiais, por exemplo).

A sinopse do caso que deu origem ao tribunal foi a seguinte: associações de moradores de três bairros do fictício Município de Porto Feliz denunciam a dificuldade de obtenção de atendimento médico nos postos de saúde e solicitam providências ao CMS. O CMS não toma providências; uma gestante vem a falecer; a família e amigos denunciam o CMS ao Ministério Público, acusando-o de: (1) conduta omissiva, (2) inércia no exercício do controle social, (3) descaso com a comunidade, (4) irresponsabilidade na aprovação do Plano Municipal de Saúde, (5) negligência na fiscalização da prestação de serviços de saúde no município, tendo como conseqüência a morte de uma gestante no oitavo mês de gravidez.

Foram montados dois tribunais. No período da manhã, houve preparação com a leitura do caso, material de apoio e definição dos personagens, com exceção do papel de juiz, desempenhado por um monitor. Cada conselheiro recebeu uma pasta com material para a defesa e acusação contendo os "autos do processo", uma cartilha do SUS, textos sobre atribuições do Conselho, hipertensão/eclâmpsia e sobre atendimento nos postos de saúde, as leis 8.080 e 8.142 , trechos da Constituição sobre a saúde e trechos do Estatuto da Criança e do Adolescente.

\section{Resultados}

Dos 40 que responderam ao questionário, 27 eram mulheres, com predominância da raça branca e faixa etária acima de 30 anos. Quanto à escolaridade, 28 tinham segundo e terceiro grau 
completos. Há uma grande diversidade de profissões concentradas no setor de serviços, com predomínio das profissões científicas e técnicas. A maioria já teve experiência participativa (24), em geral, por período superior a dois anos. Apesar de o evento ter ocorrido na capital, a origem dos participantes mostrou diversidade: 15 pertenciam a municípios com até $10 \mathrm{mil} \mathrm{ha-}$ bitantes, 10 entre 10-100 mil e 14 com mais de 100 mil habitantes, que nesse caso significa o município de Florianópolis.

Quanto ao principal problema de saúde do município, foram citados em ordem de importância: infra-estrutura e atendimento, algum tipo de morbidade e problemas ambientais. $\mathrm{Na}$ Tabela 1, apresentam-se estes dados com uma síntese do perfil dos Conselheiros.

Houve unanimidade na aceitação positiva do tribunal citando-se como principais argumentos “aquisição de conhecimentos" (24) e por ser "participativo, democrático e dinâmico" (17). Ainda que em menor proporção, falou-se também em "boa organização, metodologia e didática” (4). Essa afirmação foi confirmada quando 39 conselheiros disseram que usariam a técnica em seu município referindo razões semelhantes (conhecimento/sensibilização 18, objetivo/ seriedade/prática 4 , participativo 4 , validade 4 e metodologia 2) (Figuras 1 e 2). Foram as seguintes as notas atribuídas ao tribunal quanto ao seu objetivo de fazer refletir sobre o papel do conselheiro: 25 participantes atribuíram 9 a 10, seis nota 8 e quatro abaixo de 7 .

No entanto, entre as atividades realizadas, o Tribunal, embora tenha ocupado mais tempo, teve menor preferência que as reuniões simuladas, sendo que cerca da metade dos participantes refere ter gostado do conjunto. Nota-se menor preferência por atividades cognitivas formais (Figura 3).

Para 14 dos 40 conselheiros, não houve dificuldade na aplicação da técnica, 12 referiram como problemático o tempo e 9 , falta de clareza.

A análise qualitativa confirmou aspectos referentes à percepção de suas características dinâmica e participativa. Diante da informação de que haveria uma encenação com representação de personagens, as reações foram diversas, mas apenas uma pessoa manifestou desagrado, pedindo para ser ouvinte. As demais demonstraram curiosidade permeada por insegurança diante do papel inesperado de ator.

Houve interesse e expectativa na definição dos personagens: "você de advogado de defesa e o fulano de acusação, vai sair faísca”, divergências na preparação dos argumentos que se perpetuam no coffee break, e discussões quanto a ensaiá-los e não somente transcrevê-los.
Os participantes que optaram pelo corpo de jurados se mostraram mais apáticos, realizando a leitura do material sem muita discussão. Os grupos de acusação e defesa eram os mais motivados, tecendo comentários e reflexões, algumas referentes à boa preparação do material, o que coincide com a avaliação quantitativa. A observação evidenciou um aspecto não referido no questionário, a relação de realidade do caso proposto com situações vivenciadas pelos conselheiros. Algumas dúvidas surgiram em relação ao réu, se seria o secretário, o presidente do Conselho, um conselheiro ou um representante do conselho. Os monitores esclareceram que o réu era o conselheiro.

Quanto ao papel do Conselho, diversas concepções foram expressas, algumas demonstrando falta de clareza e desinformação:

"Não deliberamos nem executamos".

"O Conselho tem papel igual ao do gestor... o Conselho não tem papel executivo".

"Não sabia que o papel do Conselho e do conselheiro fosse tão necessário".

Para outros, o Conselho deveria preocuparse com o direito à saúde dos excluídos socialmente "Enquanto não tivermos Conselho autêntico que trabalhe, que vai à luta e que tenha proposta para os mais pobres, humilhados e mais simples..."

Notou-se motivação na leitura das principais leis que regem os SUS, tendo sido também utilizado o Estatuto da Criança e Adolescente. Confirmou-se a carência de informação aliada ao fato dos conselheiros atribuírem esse saber a advogados ou questionando sua capacidade em adquiri-lo. Ao desempenhar seus papéis algumas pessoas sentiram dificuldades na argumentação e nas respostas às interrogações dos advogados, com uma das testemunhas desculpandose pelo nervosismo. Outros representaram seus papéis de forma entusiástica, finalizando a participação com gestos de vencedor.

Os argumentos da defesa e acusação giraram em torno dos seguintes pontos:

- A mulher, esposo e vizinha foram negligentes;

- Médico inapto;

- Negligência hospitalar;

- Auxiliar verificou a pressão arterial, solicitou o retorno da mesma mas esta não voltou;

- Omissão do Conselho que não acompanhou as deliberações;

- O Conselho deliberou, mas o executivo não encaminhou;

- Inércia no exercício do controle social;

- Descaso com a comunidade;

- Irresponsabilidade na aprovação do Plano Municipal; 
- Negligência na aprovação do Plano Municipal.

No desenvolvimento da técnica, o papel do juiz desempenhado por monitores se mostrou essencial para assegurar um clima de seriedade e formalismo à encenação.

No veredicto final, o réu foi absolvido pelos dois tribunais. Dos seis quesitos, foi considerado culpado em apenas dois, desconhecimento quanto aos seus direitos e deveres e negligência no exercício do controle, o que confirma os aspectos já levantados quanto ao conhecimento de suas funções.

Nos comentários finais, estavam de acordo com a sentença, outros nem tanto. Justificando ou discordando, refletiam que, sendo o julgamento de seus pares, a saída mais cômoda foi transferir ou compartilhar responsabilidades. Em um dos grupos de jurados, procuravam-se os "verdadeiros culpados", julgando a mulher (gestante) ou o secretário, considerando terem posto "a pessoa errada na cadeira".

\section{Discussão e conclusão}

O manuseio do material de apoio, as discussões e a motivação de criar argumentos para o tribunal permite mapear o conhecimento acerca do papel do Conselho e torna os participantes sensíveis à troca e à procura de informações.

A aceitação da técnica coincide com os resultados observados em trabalho anterior (Conill et al., 1998), demonstrando sua utilidade em públicos distintos, o que é importante para o desenvolvimento e a continuidade da aplicação de novas estratégias em educação. Nas duas situações estudadas, a preferência por este tipo de atividade foi nitidamente superior ao das cognitivas formais. Neste caso, a aquisição de conhecimento foi a principal razão enunciada para essa aceitação, superando seu dinamismo. É possível que essa apreciação reflita um viés decorrente da existência, nesta oficina, de um conjunto maior de atividades, tendo sido o tribunal a última a ser realizada. Um aspecto interessante desta avaliação é o fato de que, apesar de ocupar mais tempo entre as atividades previstas e necessitar maior trabalho em sua preparação, esta técnica teve menor preferência que as reuniões simuladas.

O perfil dos conselheiros da região metropolitana é caracterizado pela presença importante de mulheres, acima de 30 anos, tendo como particularidade um alto grau de escolaridade, predomínio de profissões da área técnica e científica e vivência participativa. Isto coincide com a situação encontrada no Estado por Funk

\begin{tabular}{|c|c|}
\hline \multicolumn{2}{|c|}{$\begin{array}{l}\text { Perfil dos } 40 \text { Conselheiros que responderam ao questionário. } \\
\text { Oficina de Capacitação, Florianópolis, Santa Catarina, Brasil, } 1999 .\end{array}$} \\
\hline Variável & $\mathrm{n}$ \\
\hline \multicolumn{2}{|l|}{ Sexo } \\
\hline Feminino & 27 \\
\hline Masculino & 13 \\
\hline \multicolumn{2}{|l|}{ Idade } \\
\hline Até 29 anos & 2 \\
\hline 30 a 49 anos & 19 \\
\hline 50 a 79 anos & 12 \\
\hline $\mathrm{N} / \mathrm{R}$ & 7 \\
\hline \multicolumn{2}{|l|}{ Ocupação } \\
\hline Profissões científicas e técnicas & 17 \\
\hline Trabalhador serviços & 11 \\
\hline Trabalhador agrícola & 4 \\
\hline Proprietário & 1 \\
\hline Aposentado & 5 \\
\hline Do lar & 1 \\
\hline Outros & 1 \\
\hline \multicolumn{2}{|l|}{ População do município } \\
\hline Até 10.000 habitantes & 15 \\
\hline 10.000 a 100.000 habitantes & 10 \\
\hline$>100.000$ habitantes & 14 \\
\hline$N / R$ & 1 \\
\hline \multicolumn{2}{|l|}{ Raça } \\
\hline Branca & 35 \\
\hline Negra & 2 \\
\hline $\mathrm{N} / \mathrm{R}$ & 3 \\
\hline \multicolumn{2}{|l|}{ Escolaridade } \\
\hline 1o grau incompleto & 4 \\
\hline 1o grau completo & 3 \\
\hline 2 o grau incompleto & 4 \\
\hline 2o grau completo & 12 \\
\hline 3o grau incompleto & 0 \\
\hline 3o grau completo & 16 \\
\hline Pós-graduação & 1 \\
\hline \multicolumn{2}{|l|}{ Expectativa participativa } \\
\hline \multicolumn{2}{|l|}{ Sim } \\
\hline Menos 1 ano & 4 \\
\hline 1 a 2 anos & 7 \\
\hline 2 anos & 2 \\
\hline Mais de 4 anos & 22 \\
\hline Total & 35 \\
\hline Não & 4 \\
\hline $\mathrm{N} / \mathrm{R}$ & 1 \\
\hline \multicolumn{2}{|l|}{ Problemas de saúde referidos* } \\
\hline Estrutura/processos & 20 \\
\hline Morbidade & 16 \\
\hline Ambiente & 9 \\
\hline Outros & 2 \\
\hline$N / R$ & 3 \\
\hline
\end{tabular}

* Possibilidade de múltiplas respostas. 
Figura 1

Distribuição das razões para aceitação positiva da técnica.

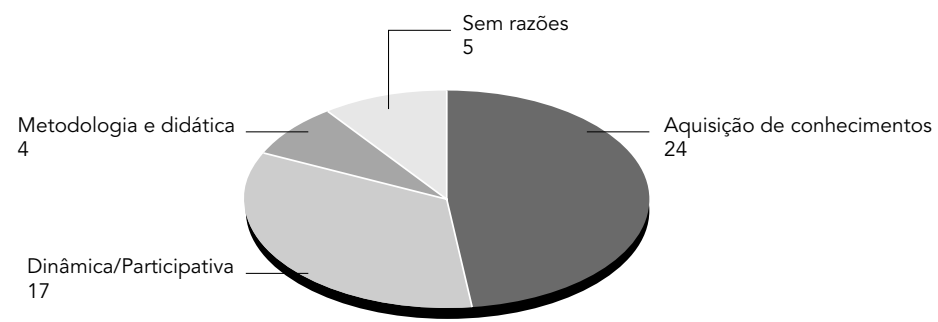

Obs: Admite múltiplas respostas.

Figura 2

Distribuição das razões para utilização da técnica em seu município.

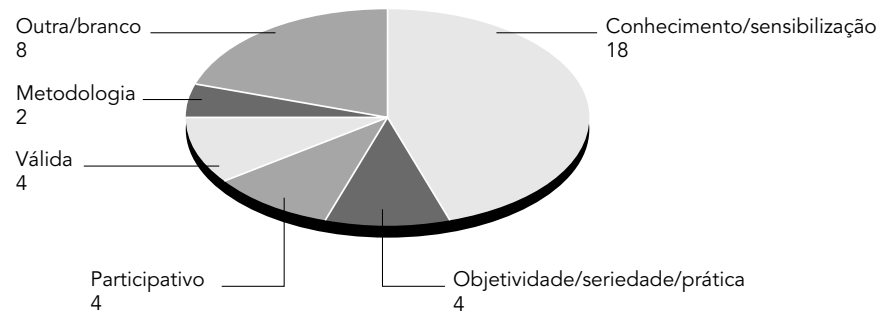

Figura 3

Distribuição da preferência dos participantes por atividades.

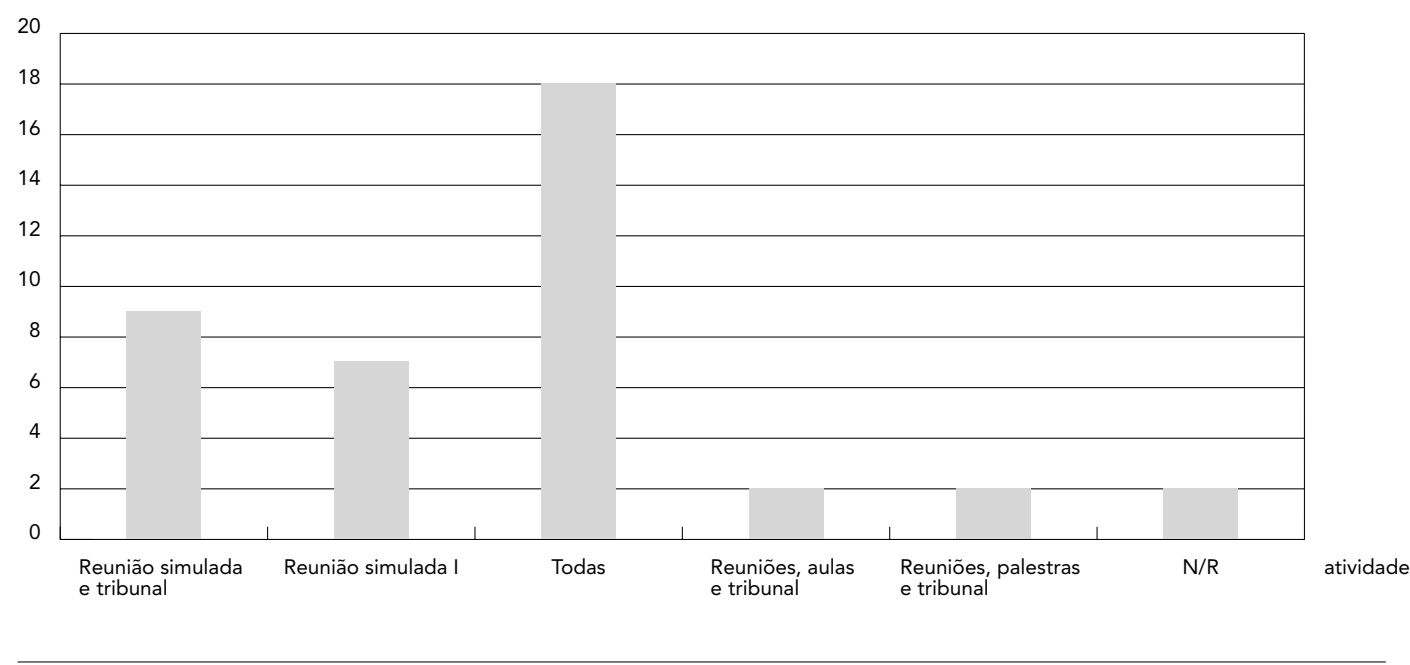

et al. (2000) e pode também ter facilitado sua aceitação.

Na divulgação do evento, explicitou-se a realidade de que alguns Conselhos existiam em decorrência de necessidades formais, mas não estavam em atividade. A situação do controle social em Santa Catarina não parece ser distinta das demais regiões do país, onde nota-se a existência formal dos Conselhos, mas dificuldades para reunir os Conselheiros (Carvalho, 1995).

Os indicadores de saúde da mulher são comparativamente desfavoráveis no cenário nacional, principalmente quando se considera a posição que o Estado ocupa em termos sócio-econômicos. Além de descrever e avaliar uma estratégia inovadora, este texto assinala a importância da ligação das temáticas, gênero e controle social. Há dificuldades na capacitação de conselheiros, mas esse processo tem demonstrado avanços (Santos et al., 2000). A mulher é uma das principais usuárias de serviços (Mendonza-Sassi \& Béria, 2001), sendo importante a inclusão de questões relacionadas à sua saúde nessas capacitações.

Algumas dificuldades foram apontadas por profissionais que atuam na área da saúde, educação popular e comunicação em curso realizado no Estado (Grupo de Pesquisa Educação Popular/Grupo Interinstitucional de Comunicação e Educação em Saúde de Santa Catarina, 2000). Salientam-se dificuldades relacionadas com cultura, linguagem e comunicação, sendo a postura de externalidade aos processos sociais 
também considerada uma barreira. As causas/ conseqüências são colocadas fora da esfera de atuação das pessoas implicadas, em um lugar inatingível denominado sistema ou política. Assim o indivíduo sabe, ou está ou é, mas se tranqüiliza, pois as soluções são externas à sua ação. O contrário seria sentir, mover-se pela e compaixão, mudar, movimentar-se porque faz parte do contexto social no qual está inserido.

Considerando-se os esforços necessários à sua preparação, é possível que o tribunal não seja superior a outras atividades de caráter prático e vivencial, que devem igualmente ser ex- perimentadas, como neste caso, as reuniões simuladas. Esta técnica parece interessante quando faz-se necessário mapear conhecimentos e promover o aparecimento de concepções latentes frente a temáticas novas e polêmicas. Auxilia a ultrapassar discursos prontos no caminho de vivências reflexivas e, quem sabe, contribui na superação de tais externalidades.

É necessário ousar inovações nas capacitações e estes resultados legitimam tais iniciativas, apontando para a confiabilidade e para a validade de conteúdo e de construção da técnica Tribunal do Júri.

\section{Agradecimentos}

As autoras agradecem a Clair Castilhos Coelho pelas idéias inovadoras e por sua participação juntamente com Vera Lúcia Fermiano, Maria Elizabeth Peixoto Luna e Rosana De Paola na produção da oficina que serviu de base para o estudo. 


\section{Referências}

BUSNELLO, E. D., 1986. Dinâmica de grupo, fundamentos, delimitação do conceito, origens e objetivos. In: Grupoterapia Hoje (L. C. Osório, org.), pp. 15-20, Porto Alegre: Editora Artes Médicas.

CARVALHO, A. I., 1995. Conselhos de Saúde no Brasil: Participação Cidadã e Controle Social. Rio de Janeiro: FASE/Instituto Brasileiro de Administração Municipal.

CONILL, E. \& MEISTER, R., 1988. Puxando os fios do novelo: Subsídios para a elaboração de um perfil de assistência à saúde da mulher. In: A Mulher e a Saúde (L. M. Silva, org.), pp. 102-113, Cadernos do Núcleo de Estudos e Pesquisas sobre a Mulher. Belo Horizonte: Universidade Federal de Minas Gerais.

CONILL, E. M.; PIERALISI, C. A.; PERES, M. A. A.; CASTILHOS, C.; ORTIGA, A. B.; LI, T. T. R. \& NASCIMENTO, S., 1998. O homem público em julgamento: Avaliação da técnica "tribunal do júri” para dirigentes municipais em Santa Catarina. Cadernos de Saúde Pública,14:857-861.

CONTANDRIOPOULOS, A. P.; CHAMPAGNE, F; DENIS, J. L. \& PINEAULT, R., 1997. A avaliação na área da saúde: Conceitos e métodos In: Avaliação em Saúde. Dos Modelos Conceituais à Prática na Análise da Implantação de Programas (Z. M. A. Hartz, org.), pp. 29-45, Rio de Janeiro: Editora Fiocruz.

CONTANDRIOPOULOS, A. P.; CHAMPAGNE, F.; POTVIN, L.; DENIS, J. L. \& BOYLE, P., 1994. Saber Preparar uma Pesquisa. São Paulo: Editora Hucitec/Rio de Janeiro: ABRASCO.

FUNK, I. C. P.; ORTIGA, A. M. B. \& NASSAR, S. V. J., 2000. Perfil dos Gestores e Conselheiros Municipais de Saúde dos Municípios Habilitados pela Norma Operacional Básica 01/93, no Estado de Santa Catarina. Relatório de Pesquisa. Florianópolis: Secretaria Estadual de Saúde/Universidade Federal de Santa Catarina. (mimeo.)

GRUPO DE PESQUISA EDUCAÇÃO POPULAR/GRUPO INTERINSTITUCIONAL DE COMUNICAÇÃO E EDUCAÇÃO EM SAÚDE DE SANTA CATARINA, 2000. Educação Popular e Saúde: Diálogos com a Vida. Caderno de Debate. Florianópolis: Fundação Nacional de Saúde/Ministério da Saúde.

IBGE (Fundação Instituto Brasileiro de Geografia e Estatística), 2001. Censo Demográfico 2000 - Dados Preliminares. 25 Setembro $2001<$ http://www.ibge. gov.br/ibge/estatística/população/censo2000/ sinopse.php?tipo $=21 \mathrm{~b} 4 \mathrm{f} 42>$.

LUNA, M. E.; ANJOS, M. D.; COELHO, C. C.; FERMIANO, V. L. \& DE PAOLA, R., 1999. Relatório Controle Social do SUS e Saúde da Mulher: Oficina Didática para Conselheiros Municipais de Saúde. Florianópolis: Associação Casa da Mulher Catarina. (mimeo.)

MENDOZA-SASSI, R. \& BÉRIA, J. H., 2001. Utilización de los servicios de salud: Una revisión sistemática sobre los fatores relacionados. Cadernos de Saúde Pública, 17:819-832.
MS, (Ministério da Saúde), 1984. Assistência Integral à Saúde da Mulher: Bases de Ação Programática. Brasília: Centro de Documentação, Ministério da Saúde.

MS (Ministério da Saúde), 1994. Programa de Saúde da Família - Saúde Dentro de Casa. Brasília: Fundação Nacional de Saúde/Ministério da Saúde.

MS (Ministério da Saúde), 1997. Dados da Cobertura de Pré-Natal Segundo Regiões e Santa Catarina. 28 Agosto 2001 <http://web.saude.sc.gov.be/perfil/ $\mathrm{fdb} /$ prop-gest.htm>.

MS, (Ministério da Saúde), 1998. Saúde da Família: Uma Estratégia para a Reorientação do Modelo Assistencial. Brasília: Ministério da Saúde.

MS (Ministério da Saúde), 1999. Diretrizes Nacionais para Capacitação de Conselheiros de Saúde. Brasília: Ministério da Saúde/Conselho Nacional de Saúde.

ORTIGA, A. M. B., 1999. Efeitos da Municipalização no Acesso e na Integralidade dos Serviços de Saúde Blumenau, SC, 1994-1998. Dissertação de Mestrado, Florianópolis: Departamento de Saúde Pública, Universidade Federal de Santa Catarina.

PEIXOTO, H. C. G., 1977. Mortalidade em Santa Catarina. Aplicação do Indicador Anos Potenciais de Vida Perdidos. Dissertação de Mestrado, Florianópolis: Departamento de Saúde Pública, Universidade Federal de Santa Catarina.

REDE NACIONAL FEMINISTA DE SAÚDE E DIREITOS REPRODUTIVOS/FUNUAP (Fundo de População das Nações Unidas)/FUNDAÇÃO FORD, s.d. Controle Social, uma Questão de Cidadania: Saúde é Assunto para Mulheres. São Paulo: Rede Nacional Feminista de Saúde e Direitos Reprodutivos.

REGIA, M.; LIMA, M. J.; BAIÃO, I.; XAVIER, D.; CAMURÇA, S. \& OLIVEIRA, E. M., 1988. Como Trabalhar com Mulheres. Petrópolis: Editora Vozes.

SANTOS, N. R.; FERREIRA, B. M. S.; CUNHA, C. A. C.; REIS, D.; CARTAXO, F; RIBEIRO, G. C.; FIGUEIREDO, L. M. C.; FACCENDA, M. C. B.; HENRIQUE, P; SILVA, P. J. S. \& NEDEL, R. G., 2000. A prática do controle social através dos conselhos de saúde. $D i$ vulgação em Saúde para Debate, 22:71-91.

SES-SC (Secretaria de Estado da Saúde de Santa Catarina), 2001. Conselhos Municipais de Saúde. Relatório Preliminar. Florianópolis: SES-SC.

VIANNA, R.; MARCONDES, R.; LESSA, Z. \& AUGUSTO, M., 1991. Educação em Saúde e Mobilização Comunitária, Manual de Técnicas. São Paulo: Centro de Apoio ao Desenvolvimento de Assistência Integral à Saúde, Secretaria de Estado de São Paulo.

VITIELLO, N. (org.), 1997. Manual de Dinâmicas de Grupo. São Paulo: Iglu Editora.

Recebido em 22 de novembro de 2001

Versão final reapresentada em 6 de agosto de 2002 Aprovado em 29 de novembro de 2002 